\title{
The Perceptions of Patient Copayment on the Reported Adherence to Prescription Medication
}

\author{
Velisha A. Perumal-Pillay ${ }^{1}$, Shiraz R. Alli ${ }^{1} \&$ Fatima Suleman ${ }^{1}$ \\ ${ }^{1}$ Discipline of Pharmaceutical Sciences, School of Health Sciences, University of KwaZulu-Natal, South Africa \\ Correspondence: Professor Fatima Suleman, Discipline of Pharmaceutical Sciences, University of KwaZulu-Natal, \\ Private Bag X54001, Durban 4000, South Africa. Tel: 27-31-260-7941. E-mail: sulemanf@ukzn.ac.za
}

Received: August 17, 2018 Accepted: September 18, 2018 Online Published: October 13, 2018

doi:10.5539/gjhs.v10n11p105 URL: https://doi.org/10.5539/gjhs.v10n11p105

\begin{abstract}
Background: In South Africa, a large proportion of the population is dependent entirely on the publicly funded system for healthcare, while private funding covers only a small percentage of those who can afford to pay for health insurance or out-of-pocket payments. Non-compliance to medical treatment is a well-known problem and may lead to an increase in healthcare costs.

Objectives: To investigate how the perception of prescription copayments influences medication use and the effect of this on safe and correct medicine usage

Methods: The study was conducted with a sample of patients from the Umbilo suburb of eThekwini, South Africa. Participants were members of a medical scheme and completed a questionnaire after informed consent. The questionnaire design included an eight-item scale to ascertain the degree of concern regarding prescription costs. Quantitative data were analysed using descriptive statistics; associations between household characteristics and outcomes were explored using odds ratios and chi square analysis.
\end{abstract}

Results: Overall $82 \%$ of the participants reported that prescription cost was a major factor that influenced medication collection. The association between demographic data and concern scale was assessed and revealed that participants had an increased concern with meeting prescription costs (OR 1.73, 95\% CI 0.66-4.52). Most (93\%) of the participants with a salary less than ZAR10 000 indicated a concern with prescription costs (chi square $=21.7, d f=2, \mathrm{p}<0.05$ ).

Conclusion: The study indicated that prescription cost posed as a barrier to medication adherence as the copayment affected patients' decisions to continue optimal treatment.

Keywords: adherence, medicine cost, out-of-pocket payment, prescription

\section{Introduction}

The South African healthcare system consists of both public and private healthcare sectors. In South Africa, healthcare is financed through a combination of private and public resources: general tax, private insurance and out-of-pocket payments (Ataguba \& McIntyre, 2012). Medical aid schemes provide an integral part in financing their members if and when a medical emergency occurs. Only $17 \%$ of South Africans have medical insurance that provides first-class healthcare (Gray, Riddin, \& Jugathpal, 2016).

As such, in South Africa, a large proportion of the population depends entirely on the publicly funded system for healthcare whilst private funding covers only those who can afford to pay for it (Ataguba \& McIntyre, 2012). Membership on medical schemes is voluntary (Ataguba \& McIntyre, 2012), and schemes must cover the prescribed minimum benefits (PMB) package (Ataguba \& McIntyre, 2012) which is based on a scale of benefits which specifies the proportion of reimbursement required for the service provided (van den Heever, 2012). PMBs describe the minimum level of care that must be funded by all private medical insurers as defined in the Medical Schemes Act (131 of 1988) by the South African National Medicines List Committee) (Nicolosi \& Gray, 2009). All other conditions are treated by means of formulary management in order to contain costs. However, the community pharmacists are often responsible for explaining to patients the reasons their medical aid scheme does not pay for an item. Usually, it is the reason that the medicine specified does not form part of that scheme's medicines formulary or the medicine requested is priced above the capped cost in the formulary, which subsequently forces the patient to pay an amount in cash as a copayment. 
Cost-sharing or copayments is a world-wide accepted expenditure-control strategy by insurance schemes (Strickland \& Hanson, 1996), as the moral-hazard phenomena (i.e. individuals with health insurance will overuse health services because they bear no portion of the financial burden) is reduced thereby decreasing the consumer demand (van den Heever, 2012). Such cost-related restriction could be a mechanism for worse health outcomes among low-income and other vulnerable populations who lack adequate insurance coverage (van den Heever, 2012); (Norris et al., 2016). Studies have demonstrated that copayments on medication reduce the consumption of both non-essential and essential medicines, and the latter can lead to worse health outcomes (Strickland \& Hanson, 1996); (Sinnott, Buckley, O'Riordan, Bradley, \& Whelton, 2013; Sinnott, Whelton, Franklin, \& Polinski, 2017). A study conducted in New Zealand showed that patients who did not collect prescription medications due to cost are at increased risk of a subsequent decline in health (Jatrana, Richardson, Norris, \& Crampton, 2015). Non-compliance to medical regimes is a well-known problem and may lead to an increase in hospital admissions (Atella, Schafheutle, Noyce, \& Hassell, 2005; Sinnott et al., 2017) which ultimately results in increased healthcare costs. Adherence to treatment is thus of concern to schemes and prescribers alike.

Adherence is defined as the extent to which patients take medications as prescribed by their healthcare providers (Taira, Wong, Frech-Tamas, \& Chung, 2006). A review article published by Tiara et al, (2006) regarding adherence revealed that adherence rates are typically higher amongst patients with acute conditions as compared to patients with chronic conditions (Taira et al., 2006). Healthcare providers advise patients of the adverse effects of non-adherence but not all patients heed the warnings (Wysowski, Armstrong, \& Governale, 2003). Lack of compliance with prescribed medication is a well-known problem outlined in medical literature (Eaddy, Cook, O'Day, Burch, \& Cantrell, 2012).

Neugut et al., (2011) indicated that in patients who continued their hormonal therapy, $28 \%$ were non-adherent at some point. This is a valid point as one may think that because a patient continues therapy for a long time they are usually $100 \%$ adherent. This study indicated that higher copayments by the patients were negatively associated with adherence and persistence.

It was therefore important to assess the situation in a South African population in order to inform policy recommendations with regard to copayments of medicines in the private healthcare sector, and to determine impacts of high copayments on patients' behaviours with regard to medication adherence. Our study reports on how the perception of prescription copayments affects medication use as well as the effect this has on safe and correct medicine usage for a sample of patients who reside in the Umbilo suburb in eThekwini, KwaZulu-Natal, South Africa. The null hypothesis was that the perceptions of copayments do not affect adherence or increase adherence to medication regimens.

\section{Methods}

\subsection{Study Design}

This was a prospective, quantitative study and achieved by conducting house-to-house surveys using a questionnaire.

\subsection{Setting}

This research was conducted in the Umbilo suburb of Durban, South Africa, targeted at a cluster sample of patients within the community.

\subsection{Study Population and Sampling Strategy}

Only eligible study participants were included, based on the following characteristics: participants who were members of a medical aid scheme and were over the age of 18 years residing in the Umbilo suburb; participants who suffered from chronic conditions and were on medication for these conditions; participants who incurred copayments on their prescribed medicines; and participants had to be able to understand and communicate in English. Participants were excluded if they were not part of a medical aid scheme, not on chronic medication as well as those patients who were on chronic medication but did not incur copayments.

The sample population was determined by using the cluster sampling method to allow for ease of data collection. ${ }^{11}$ Umbilo consists of many sub districts (areas such as Carrington Heights, Glenmore, Manor Gardens, Umbilo industrial sector, and Berea). Cluster samples of 32 households were obtained from each area using a simple random sampling method. The surveys were conducted, on a "willingness to participate" basis. To ensure a $95 \%$ confidence interval for proportions of no wider than $\pm 5 \%$ an approximate number of 150 participants were required to make the results of the study statistically significant. 152 participants from 160 households were interviewed and results were documented accordingly. The time per interview was approximately 15-20 minutes 
and was conducted at the local households.

\subsection{Data Collection}

The questionnaire targeted medicine-related behaviors regarding difficulties in filling prescriptions received from doctors as well as patient perceptions regarding the cost of medication. Participants were asked whether in the last six months they had experienced any difficulty with respect to being unable to collect a prescription because the medication would cost too much; delaying the doctor visit due to the fear of the cost of the medicines prescribed; cut down the dose of the prescription to make the medication last longer; used medication prescribed to someone else because it would have cost too much to purchase their own; and their perception of the costs of medication in South Africa, amongst others.

Also included in the questionnaire was an eight-item scale (using Likert response format), to ascertain the degree of concern regarding the cost of the prescription. A scale score was computed (range 1-24) where 1-8 represented no concern, 9-16 indicated slight concern and 17-24 represented concern. At the end of the questionnaire was an open-ended question for any other comments regarding medication copayment. Responses were documented accordingly. Socio demographic information including gender, ethnicity, age, marital status, employment status and approximate monthly income was obtained.

\subsection{Data Analyses}

The scale score was calculated, dividing the data into three equal strata. The demographic data as well as household data was included in the study as the associations between demographic characteristics and concerns was assessed using odds ratios and chi square analysis. Statistical analysis was conducted using the Statistical Package for Social Sciences (SPSS) software program, version 21. Data proportions and descriptive statistics were calculated using a $95 \%$ confidence interval. The questionnaire was designed to ascertain the relationship between prescription cost and adherence to prescription regimens.

\subsection{Ethical Considerations}

Ethical approval was obtained from the University of KwaZulu-Natal's Biomedical Research Ethics Committee prior to commencing data collection (BE 481/14). Informed consent was obtained from each participant and voluntary participation was stressed. Participants were allowed to withdraw from the study at any time without any consequences. Privacy was assured such that, no household or patient identifying information was recorded. A study identifier number was allocated to each questionnaire and recorded to ensure confidentiality.

\section{Results}

All participants were members of medical schemes either self-funded or otherwise. A total of 152 out of 160 (response rate 95\%) patients from various socio-economic backgrounds participated in the study. Demographic data was recorded (see Table 1) which indicates almost a uniform distribution across gender, age and race groups. Chronic health conditions of participants included: diabetes (34.89\%), hypertension (24.34\%), cholesterol (19.07\%), asthma/allergy (12.5\%), anaemia (1.97\%) and other (11.18\%). Majority (66\%) of the respondents were married.

Table 1. Demographic characteristics of the interviewed population

\begin{tabular}{lll}
\hline Demographic Characteristics & Number of participants & \% of participants $(\mathbf{n}=\mathbf{1 5 2})$ \\
\hline Sex: & & 53 \\
Male & 81 & 47 \\
Female & 71 & \\
\hline Race: & & 36 \\
White (Caucasian) & 55 & 15 \\
Indian & 23 & 34 \\
African & 51 & 15 \\
Other & 23 & \\
\hline
\end{tabular}




\begin{tabular}{lll}
\hline Age Groups: & 31 & 20 \\
$18-30$ years & 56 & 37 \\
31-45years & 41 & 27 \\
46-60years & 24 & 16 \\
>60years & & \\
\hline Marital status: & 101 & 66 \\
Married & 15 & 10 \\
Divorced & 36 & 24 \\
Single & & \\
\hline
\end{tabular}

Table 2 shows the reported patient behaviours related to prescription cost. Overall, $96 \%$ of participants indicated that prescription medicines were too expensive and $93 \%$ of participants therefore opted to use a medicine they already had at home from a previous illness because it cost too much to pay for a new prescription. Furthermore, $91 \%$ of participants were unable to buy all the medicines prescribed by the doctor due to the cost and $82 \%$ of the participants reported that prescription cost was the major factor that influenced medication collection. The delay to visit the doctor was also a common behaviour practiced by participants (84\%) and showed a strong concern with respect to the cost of buying the medicines if prescribed.

Table 2. Reported behaviors regarding prescription cost

\begin{tabular}{|c|c|c|c|}
\hline Behaviour & $n(n=152) \%$ & $\%$ & $95 \% \mathrm{CI}$ \\
\hline Not been able to get a refill of a prescription because it was too expensive & 124 & 82 & $76-88$ \\
\hline $\begin{array}{l}\text { Decided to wait before seeing a doctor because you were worried about the cost of buying } \\
\text { medicines that may be prescribed }\end{array}$ & 128 & 84 & $78-90$ \\
\hline Not been able to buy all of the medicines prescribed by your doctor because of the cost & 138 & 91 & $86-96$ \\
\hline Cut down the dose of a prescription to make it last longer because of the cost & 89 & 59 & $51-67$ \\
\hline $\begin{array}{l}\text { Used a medicine that you have had at home from a previous illness because it cost too much } \\
\text { to pay for a new prescription }\end{array}$ & 141 & 93 & $89-97$ \\
\hline Used a medicine prescribed for someone else because it cost too much to get your own & 61 & 40 & $32-48$ \\
\hline $\begin{array}{l}\text { Shared a medicine prescribed for one person between family members because of the cost of } \\
\text { paying for a new prescription }\end{array}$ & 74 & 49 & $41-57$ \\
\hline Do you believe prescription medicines are too expensive & 146 & 96 & $93-99$ \\
\hline
\end{tabular}

Seventy seven percent (118) of the participants showed a major concern with respect to the cost of prescriptions (see Table 3). This can be attributed to the salary notch being below ZAR10 000 per month as $105(69 \%)$ of participants fell within this income bracket (see Table 4).

Table 3. Concern associated with the cost of prescriptions

\begin{tabular}{lll}
\hline Concern score & $\mathbf{n = 1 5 2}$ & $\mathbf{9 5 \% C I}$ \\
\hline Concerned $^{\mathrm{a}}$ & 118 & $71-85$ \\
Slightly Concerned $^{\mathrm{b}}$ & 14 & $4-14$ \\
Not concerned $^{\mathrm{c}}$ & 20 & $8-18$ \\
\hline
\end{tabular}

Note. Scale score: ${ }^{\mathrm{a}} 17-24 ;{ }^{\mathrm{b}} 9-16 ;{ }^{\mathrm{c}} 1-8$. 
Table 4. Characteristics of individuals in households

\begin{tabular}{ll}
\hline Characteristic & \% of sample population $\mathbf{n}=\mathbf{1 5 2}$ \\
\hline$>$ 2 Adults on Medical Aid & 42 \\
Salary > ZAR10 000 & 31 \\
Salary <ZAR10 000 & 69 \\
\hline
\end{tabular}

Note. The above salary range is for the main member of the medical scheme.

The association between demographic data and concern scale was assessed and revealed that individuals with a salary of less than ZAR10 000 per month in general had an increased concern with meeting prescription costs (OR $1.73,95 \%$ CI $0.66-4.52)$. Ninety-eight (93\%) of the participants with a salary less than ZAR10 000 indicated a concern with prescription costs (chi square $=21.7, d f=2, \mathrm{p}<0.05$ ).

Statements such as 'medication cost', 'dispensing fees were too high' and the 'cost of the cheapest generic medicine still presented a copayment', were voiced by the participants in their open-ended responses. Medical schemes used reference pricing as a pricing policy, and it could be that the cheapest generic stocked by the pharmacy was still above this reference price. In summary, the results of this study indicate that prescription cost posed a barrier to medication adherence for majority of the participants as the copayment affected whether a patient would continue optimal treatment.

\section{Discussion}

This study evaluated the perception of prescription copayments for patients living in the Umbilo suburb of eThekwini, KwaZulu-Natal. The study indicated that prescription cost and related copayments affected medication adherence and influenced patients' decisions to continue optimal treatment. The study showed that participants with an income of ZAR10 000 or less had a higher chance of non-adherence to prescription regimens. This is in agreement with a similar Australian study, which confirmed that "prescription costs can pose difficulties for some Australians." (Doran, Robertson, Rolfe, \& Henry, 2004). The article by Doran et al. (2004) concluded that the patient capacity to manage the out-of-pocket copayments will place a barrier to safe prescription use. This is further reiterated in a study investigating the impact of prescription charges on people living in poverty in New Zealand which showed that even the smallest financial barriers had significant impact on low income earners' potential to access necessary medicines and hence reduced effectiveness of treatments (Norris et al., 2016).

A meta-analysis by Sinnott et al., (2013) indicated an 11\% increase in odds of non-adherence when patients were required to co-pay for their medicines. This is in agreement with the results of our study as prescription cost was the major concern for a majority of the sample population. This cost was also a major deterrent to seek medical care from medical practitioners. Another study conducted in Ireland to investigate the effect of copayments for prescription medicines on a public health insurance scheme showed that the copayment was associated with decreased adherence for both essential and non-essential medicines (Sinnott, Normand, Byrne, Woods, \& Whelton, 2016) whilst a study conducted in Spain amongst publicly insured patients showed that a uniform capped low co-payment of one Euro per prescription resulted in major reductions in medicine consumption and to a much greater extent among patients who previously had no-fee for prescriptions (García-Gómez, Mora, \& Puig-Junoy, 2018). A study investigating price responsiveness for mental healthcare according to changes of copayments in the Dutch universal mandatory health insurance scheme showed decreased mental healthcare utilization when copayments were introduced (Lambregts \& van Vliet, 2018).

As indicated by Reed et al., (2005), patients who are faced with a copayment commonly shift toward seeking medical care from other available alternatives. This is true for participants of our study, as $84 \%$ opted to delay visiting a doctor and $93 \%$ of the study participants used medication from a previous illness due to the costs involved with having to purchase new medicines prescribed.

Other studies have indicated the advantages of lower or no copayments. One such study demonstrated that reductions in copayments for chronic medications led to an increase in adherence, thereby decreasing non-adherence rates for patients residing in Massachusetts, Boston, USA (Chernew et al., 2008). A similar response was expressed by many of the study participants, indicating that prescription copayments are a global concern. A study conducted in Wales, UK to measure the impact of the phased abolition of prescription co payments showed a small increase in dispensing for the 14 selected medicines when co-payments were reduced. This suggested that there was probably a group of non-exempt patients who were not completely compliant with prescribed treatment before the introduction of the abolition policy and that the policy may have contributed to 
decreasing these patients' non - adherence which should ultimately positively impact on health (Alam, Cohen, Dunstan, Hughes, \& Routledge, 2018). These scenarios pose as possible solutions to lowering and/or eliminating cost-sharing altogether in the interest of improving overall health outcomes.

Finding savings in spending on prescription medicines without diminishing their capability to contribute to improved care and save money over a period of time, is vital but difficult and policy makers are faced with this challenge. South Africa has a policy of mandatory offer of generic substitution which obligates a pharmacist to offer the patient a cheaper alternative of a medicine unless specifically instructed by the prescriber not to substitute. However, this may be the cheapest generic available at the pharmacy and not necessarily the cheapest generic on the market. Possible policy options to maximize the use of generics at a reduced price could include referencing the price of generics in relation to the originator medicines, but at a percentage much lower than the originator medicine price. Studies show that legislative price controls can lead to generic price decreases and therefore, it could reduce co-payments, and increase adherence (Manova, Stoimenova, Clerfeuille, \& Petrova, 2011). According to the World Health Organization (World Health Organization, 2013), "Countries should use multiple strategies to achieve low priced generics, depending on the system and market. These strategies may include: within country reference pricing, tendering, and/or lower co-payments". Other countries can follow suit to contain costs.

Limitations of the study include the following: Participants were uneasy to reveal their income and it is possible that figures were inflated. Participants were also concerned with the consequences of their responses, as they felt compromised that information would reach their medical practitioners despite assurance that data would be aggregated and no patient identifying information would be attached. The small sample size prevents generalization to the South African population but serves as a basis for further expansion of the study.

The results of this study clearly show that copayments affect the optimal use of medicines by patients thereby suggesting to policy makers that policy changes concerning health insurance coverage and related copayments should be carefully considered and implemented to ensure minimal negative impacts on health outcomes related to non-adherence due to copayment costs. Hence, policy makers are reminded of the delicate balance between financial benefits and financial repercussions of copayment and cost-sharing policies (Sinnott et al., 2013). The effect of cost-sharing for prescription medicines differs per country. Furthermore, time since policy implementation and differences in structure between countries health systems influences the differential impact of copayment policies in international settings (Sinnott et al., 2016). This study adds a South African context to the body of knowledge on how cost-sharing policies affects globally diverse populations. It captures the experiences of a group of patients from a middle-upper income African country with copayments and enhances understanding of patients' responses to this policy thereby contributing to the limited knowledge in this area for South Africa.

\section{Conclusion}

This study suggests that prescription costs pose a major barrier for a majority of South African patients. Most of the participants voiced their opinion with regard to medication cost and admitted that it was a concern. Cost consciousness is an important factor affecting the effective use of chronic medicines. Recommendations to policy makers include reviewing PMB baskets to ensure common conditions are included without copayments for patients; to ensure direct provision of information to patients on PMB benefit options; as well as strategies to manage copayments, if required. Ultimately, a lower prescription copayment would favor medication adherence thereby reducing patient burden and allowing for proper, safe and effective use of medicines.

Further research is required to determine if copayments pose a concern across racial and income groups across South Africa, as well as coping strategies employed by families in the event that costs of copayments result in financial difficulties. Further research is required to determine patients' knowledge and awareness of reference price policies employed by medical aid schemes where copayments are not levied if patients purchase medicines at this reference price. Research into other cost-sharing models should also be explored.

\section{Competing Interests Statement}

The authors declare that there are no competing or potential conflicts of interest.

\section{References}

Alam, M. F., Cohen, D., Dunstan, F., Hughes, D., \& Routledge, P. (2018). Impact of the phased abolition of co-payments on the utilisation of selected prescription medicines in Wales. Health Economics, 27(1), 236-243. https://doi.org/10.1002/hec.3530

Ataguba, J. E., \& McIntyre, D. (2012). Paying for and receiving benefits from health services in South Africa: is 
the health system equitable? Health Policy and Planning, 27(suppl_1), i35-i45. https://doi.org/10.1093/heapol/czs005

Atella, V., Schafheutle, E., Noyce, P., \& Hassell, K. (2005). Affordability of medicines and patients' cost-reducing behaviour. Applied health economics and health policy, 4(1), 23-35. https://doi.org/10.2165/00148365-200504010-00005

Chernew, M. E., Shah, M. R., Wegh, A., Rosenberg, S. N., Juster, I. A., Rosen, A. B., . . Fendrick, A. M. (2008). Impact of decreasing copayments on medication adherence within a disease management environment. Health Aff (Millwood), 27(1), 103-112. https://doi.org/10.1377/hlthaff.27.1.103

Doran, E., Robertson, J., Rolfe, I., \& Henry, D. (2004). Patient co-payments and use of prescription medicines. Australian and New Zealand Journal of Public Health, 28(1), 62-67. https://doi.org/10.1111/j.1467-842X.2004.tb00634.X

Eaddy, M. T., Cook, C. L., O’Day, K., Burch, S. P., \& Cantrell, C. R. (2012). How Patient Cost-Sharing Trends Affect Adherence and Outcomes: A Literature Review. Pharmacy and Therapeutics, 37(1), 45-55.

García-Gómez, P., Mora, T., \& Puig-Junoy, J. (2018). Does $€ 1$ Per Prescription Make a Difference? Impact of a Capped Low-Intensity Pharmaceutical Co-Payment. Applied health economics and health policy, 16(3), 407-414. https://doi.org/10.1007/s40258-018-0382-x

Gray, A., Riddin, J., \& Jugathpal, J. (2016). Health Care and Pharmacy Practice in South Africa. The Canadian Journal of Hospital Pharmacy, 69(1), 36-41.

Jatrana, S., Richardson, K., Norris, P., \& Crampton, P. (2015). Is cost-related non-collection of prescriptions associated with a reduction in health? Findings from a large-scale longitudinal study of New Zealand adults. BMJ Open, 5(11), e007781-e007781. https://doi.org/10.1136/bmjopen-2015-007781

Lambregts, T. R., \& van Vliet, R. C. J. A. (2018). The impact of copayments on mental healthcare utilization: a natural experiment. European Journal of Health Economics, 19(6), 775-784. https://doi.org/10.1007/s10198-017-0921-7

Manova, M. M., Stoimenova, A., Clerfeuille, F., \& Petrova, G. I. (2011). Impact of generic competition on market share and prices of cardiovascular medicines on the Bulgarian pharmaceutical market. Journal of Public Health, 19(1), 91-100. https://doi.org/10.1007/s10389-010-0352-8

Neugut, A. I., Subar, M., Wilde, E. T., Stratton, S., Brouse, C. H., Hillyer, G. C., . . Hershman, D. L. (2011). Association Between Prescription Co-Payment Amount and Compliance With Adjuvant Hormonal Therapy in Women With Early-Stage Breast Cancer. Journal of Clinical Oncology, 29(18), 2534-2542. https://doi.org/10.1200/jco.2010.33.3179

Nicolosi, E., \& Gray, A. (2009). Potential cost savings from generic medicines-protecting the Prescribed Minimum Benefits. South African Family Practice, 51(1), 59-63. https://doi.org/10.1080/20786204.2009.10873809

Norris, P., Tordoff, J., McIntosh, B., Laxman, K., Chang, S. Y., \& Te Karu, L. (2016). Impact of prescription charges on people living in poverty: A qualitative study. Research in Social and Administrative Pharmacy, 12(6), 893-902. https://doi.org/10.1016/j.sapharm.2015.11.001

Reed, M., Fung, V., Brand, R., Fireman, B., Newhouse, J. P., Selby, J. V., \& Hsu, J. (2005). Care-Seeking Behavior in Response to Emergency Department Copayments. Medical Care, 43(8), 810-816.

Sinnott, S. J., Buckley, C., O'Riordan, D., Bradley, C., \& Whelton, H. (2013). The Effect Of Copayments For Prescriptions On Adherence To Medicines In Publicly Insured Populations: A Systematic Review And Meta-Analysis. Value in Health, 16(3), A207. https://doi.org/10.1016/j.jval.2013.03.1048

Sinnott, S. J., Normand, C., Byrne, S., Woods, N., \& Whelton, H. (2016). Copayments for prescription medicines on a public health insurance scheme in Ireland. Pharmacoepidemiology and Drug Safety, 25(6), 695-704. https://doi.org/10.1002/pds.3917

Sinnott, S. J., Whelton, H., Franklin, J. M., \& Polinski, J. M. (2017). The international generalisability of evidence for health policy: A cross country comparison of medication adherence following policy change. Health Policy, 121(1), 27-34. https://doi.org/10.1016/j.healthpol.2016.10.009

Strickland, W. J., \& Hanson, C. M. (1996). Coping with the cost of prescription drugs. Journal of health care for the poor and underserved, 7(1), 50-62. https://doi.org/10.1353/hpu.2010.0014 
Taira, D. A., Wong, K. S., Frech-Tamas, F., \& Chung, R. S. (2006). Copayment level and compliance with antihypertensive medication: analysis and policy implications for managed care. American Journal of Managed Care, 12(11), 678-684.

van den Heever, A. M. (2012). The role of insurance in the achievement of universal coverage within a developing country context: South Africa as a case study. BMC Public Health, 12(1), S5. https://doi.org/10.1186/1471-2458-12-s1-s5

World Health Organization [WHO]. (2013). WHO Guideline on Country Pharmaceutical Pricing Policies. Geneva. Retrieved from https://www.ncbi.nlm.nih.gov/books/NBK258631/.

Wysowski, D. K., Armstrong, G., \& Governale, L. (2003). Rapid Increase in the Use of Oral Antidiabetic Drugs in the United States, 1990-2001. Diabetes Care, 26(6), 1852-1855. https://doi.org/10.2337/diacare.26.6.1852

\section{Copyrights}

Copyright for this article is retained by the author(s), with first publication rights granted to the journal.

This is an open-access article distributed under the terms and conditions of the Creative Commons Attribution license (http://creativecommons.org/licenses/by/4.0/). 